\title{
Evaluation of Pathogenic Variability Based on Leaf Blotch Disease Development Components of Bipolaris sorokiniana in Triticum aestivum and Agroclimatic Origin
}

\author{
Sabiha Sultana ${ }^{1 *}$, Sanjoy Kumar Adhikary ${ }^{1}$, Md. Monirul Islam², and Sorder Mohammad Mahbubur Rahman ${ }^{2}$ \\ ${ }^{1}$ Agrotechnology Discipline, Khulna University, Khulna 9008, Bangladesh \\ ${ }^{2}$ Biotechnology and Genetic Engineering Discipline, Khulna University, Khulna 9008, Bangladesh
}

(Received on August 23, 2017; Revised on October 28, 2017; Accepted on December 11, 2017)

Leaf blotch of wheat caused by Bipolaris sorokiniana is a major constraint to wheat production, causing significant yield reduction resulting in severe economic impact. The present study characterizes to determine and compare pathogenic variability exist/not based on components of leaf blotch disease development and level of aggressiveness due to agroclimatic condition of $B$. sorokiniana in wheat. A total of 169 virulent isolates of $B$. sorokiniana isolated from spot blotch infected leaf from different wheat growing agroclimate of Bangladesh. Pathogenic variability was investigated on a susceptible wheat variety 'kanchan' now in Bangladesh. A clear evidence of positive relationship among the components was recorded. From hierarchical cluster analysis five groups were originating among the isolates. It resolved that a large amount of pathogenic diversity exists in Bipolaris sorokiniana. Variation in aggressiveness was found among the isolates from different wheat growing areas. Most virulent isolates BS 24 and BS 33 belonging to High Ganges River Flood Plain agro-climatic zones considered by rice-wheat cropping pattern, hot and humid weather, high land and low organic matter content in soil. Positive relationship was found between pathogenic variability and aggressiveness with agro-climatic condition.

\footnotetext{
*Corresponding author.

Phone) 08801922264339, FAX) +88-041-731244

E-mail) hure jannat888@yahoo.com

(c) This is an Open Access article distributed under the terms of the Creative Commons Attribution Non-Commercial License (http:// creativecommons.org/licenses/by-nc/4.0) which permits unrestricted noncommercial use, distribution, and reproduction in any medium, provided the original work is properly cited.
}

Articles can be freely viewed online at www.ppjonline.org.
Keywords : aggressiveness, agroclimatic origin, Bipolaris sorokiniana, component, pathogenicity

Handling Associate Editor : Lee, Jungkwan

Wheat production played green revolution in ensuring food security in the population dense region of the world (Basheer-Salimia et al., 2014). Due to fast growing population of the world especially in the developing countries (Bangladesh, India, Pakistan, and Nepal) the demand of wheat is keep on increasing (Kumar et al., 2015). The present global wheat demand is about 640 Million tones and to satisfy the demand of growing population in $2020 \mathrm{AD}$, we need to produce between 840 to 1050 million tones (Rosegrant et al., 1995). In Bangladesh now-a-day wheat as a good supplement of rice plays a vital role to meet the food demand and ranked as second most important cereal crop. In the last 11 years wheat production was highest in Bangladesh (Adhikary et al., 2015) and in the last year yield reached up to 13.48 lakh tons (BBS, 2016). It has been learnt from past experiences that there are number of constraints in the successful wheat production and in the way to make dream true to feed the world growing population in coming years. One of the important causes of yield reduction in wheat is the occurrence of some diseases (Singh et al., 2015) Among the diseases, leaf blotch or foliar blight caused by Bipolaris sorokiniana (Sacc. in Sorok).Shoem (syn. Helminthosporium sativum, teleomorph (Cochliobolous sativu) is one of the most devastating in warm and humid regions of South Asian countries. The average yield loss due to leaf blotch in South Asia and India has been estimated to be $19.6 \%$ and $15.5 \%$, respectively and Yield losses reached up to $80 \%$ to $100 \%$ under most severe conditions of infection (Joshi and Chand, 2002). Rice-wheat 
rotation covering 12 million ha in South Asia. It replaced rice-fallow and has been used for the last 30 years. In this cropping system, there is a growing body of evidence that stress conditions like as low fertility and high land are increasing the severity of leaf blights (Duveiller et al., 1998a).

Leaf blotch is a destructive disease of wheat in the ricebased cropping system and these areas are characterized by high temperature and humidity in Asian country. The disease appears at the seedling stage and increases in severity with plant age. At the present time, almost all released varieties show varying degrees of leaf blotch susceptibility due to development of new races, environmental alteration and application of excessive or low fertilization but no germplasm has been found to be highly resistant because of high pathogenic variability occurring in this fungi and narrow genetic base for resistance in currently available wheat cultivars. The average wheat yield loss due to leaf blotch was estimated at 14.9\% (Alam et al., 1998; Kumar et al., 2015). Pathogenic variability of a pathogen is crucial significance in their management (Joshi et al., 2007). Cultivation of resistant varieties is the cheapest way to combat leaf blotch disease. However, resistance to leaf blotch in the commonly grown wheat cultivars of South Asia is generally unsatisfactory (Joshi et al., 2004). To control this disease an integrated approach is considered necessary with host resistance as a major component.

Host Resistance is characterized by a reduced rate of epidemic development in a host population. The reduced epidemic rate has been attributed to various components of disease development such as lower infection frequency, longer latent period, reduced spore production, shorter infectious period etc (Lancashire and Jones, 1985).

Van der Plank (1963) model of epidemic has direct relationship to the components of resistance. Many studies assert the association between components, but this can be incomplete (Lancashire and Jones, 1985). Bipolaris sorokiniana characterized by a continuous variation in symptom expression that is quantitative rather than and no physiologic specialization in the pathogen has been demonstrated. The epidemiological consequences of disease development to Bipolari ssorokiniana have been little explored, although the relative importance of some components has been investigated by means of simulation (Lancashire and Jones, 1985).

Emerging newer strains and races of rust pathogens with increased virulence can be a further threat to wheat production and productivity at the global level. Heavy yield loss due to leaf blotch disease laid down in a situation to redesign policies and many efforts were initiated from long back on the leaf blotch disease management in South-Asia (Kumar et al., 2015). Pathogenic variability among 122 Bangladeshi isolates of $B$. sorokiniana have been studied without considering agro-climatic origin (Adhikary et al., 2005). The purpose of this study was to determine and compare pathogenic variability exist/not based on components of leaf blotch disease development of $B$. sorokiniana and level of aggressiveness related to agroclimate.

\section{Materials and Methods}

Bipolaris sorokiniana isolation, identification and Monoconidial isolate preparation. Leaves with spot blotch symptoms were collected from different areas representing major agro ecological wheat growing regions of Bangladesh. Typical symptoms of the leaf blotch diseased leaf are illustrated in Fig. 1.These sites were selected based on CIMMYT's working area. Leaf samples were collected around flowering time, dried in blotting paper and taken to

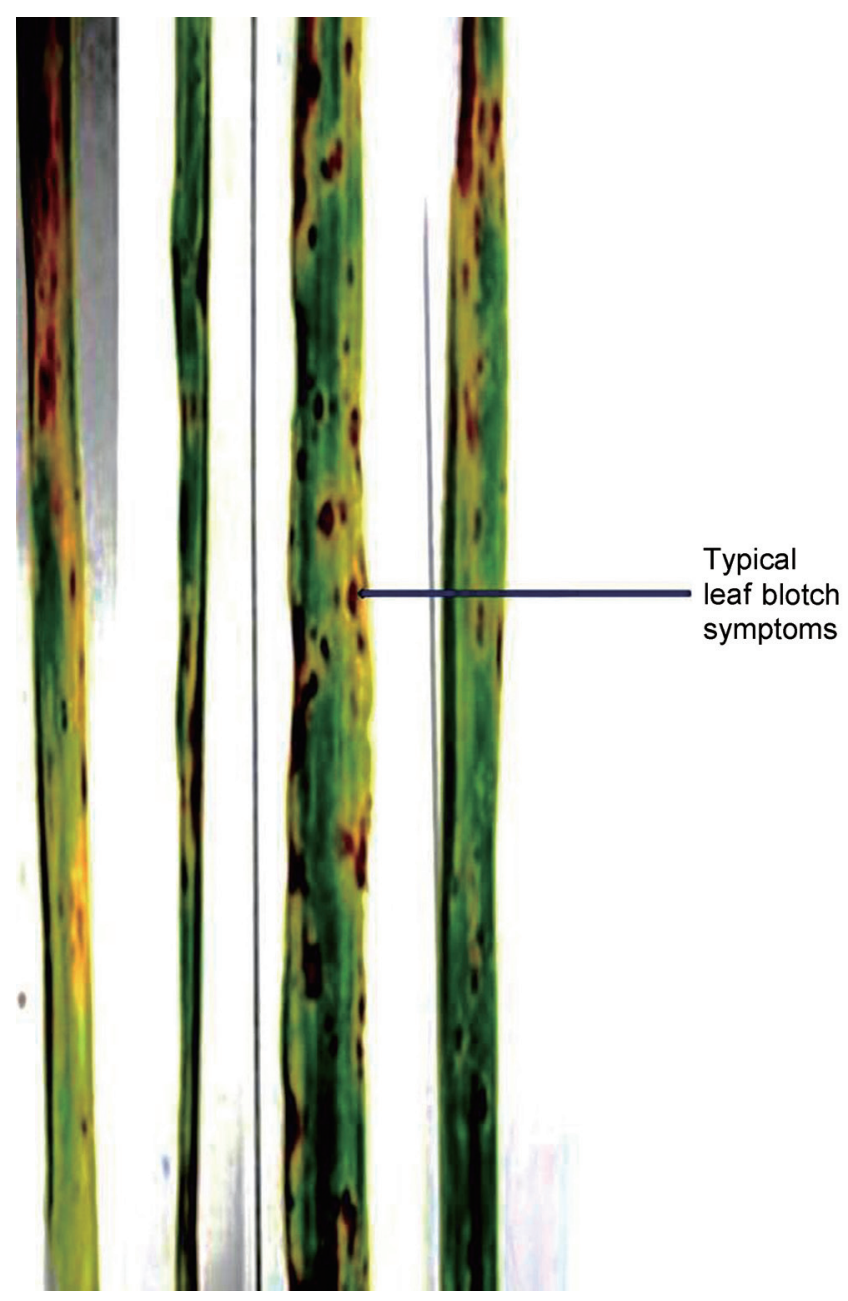

Fig. 1. Typical leaf blotch symptoms in wheat. 
the laboratory for isolation. After surface sterilization in 1\% $\mathrm{NaOCl}$ solution and rinsing in sterile distilled water, small pieces of diseased tissue were placed on $1 \%$ water agar medium before subculturing mycelium on PDA to obtain pure cultures. To avoid saprophytic bacterial growth by adding $2 \mathrm{mg}$ streptomycin sulfate powder to the plant sample on the water agar plates, by means of a scalpel.

The descriptions for morphological identification of the database Nomenclature and Species Banks were employed to identify isolated species (Robert et al., 2005).

Monoconidial cultures were produced for each isolate by diluted spore suspension was prepared from the pure cultures and then plated. Single conidia were individually transferred to new PDA plates with the help of stereobinoculars microscope and a sterile needle. Each monoconidial culture was stored at $4^{\circ} \mathrm{C}$ under PDA slants, in order to make available initial inoculum and minimize the risk of losing pathogenicity after repeated sub-culturing.

Pathogenicity assessment in a susceptible cultivar based on component. The experiment was conducted during the wheat growing season of 2013-2014 and 2014-15. Threeleaved seedlings of a susceptible variety 'kanchan' were used in the experiment. 169 isolates of Bipolaris sorokiniana were separated based on their geographic origin (Table 1). Wheat seedlings were raised in polyethylene bags (13 $\mathrm{cm} \times 10 \mathrm{~cm}$ ) containing sandy loam soil, $\mathrm{pH} 7.5$. Plants were grown in a net house until the three-leaf growth stage. Six seeds were sown per pot, and plants were thinned to three plants per pot just after emergence. Inoculum was prepared as ten days old culture of $B$. sorokiniana was used. Conidia were collected by flooding the Petri dishes with $10 \mathrm{ml}$ sterile distilled water and scraping the agar surface with a spatula to dislodge the conidia. The conidial suspension was filtered through a double layer of cheesecloth. The concentration of conidia was counted standard haemocytometer with Neubauer rulings and adjusted to $10^{3}$ conidia $/ \mathrm{ml}$. The spore suspension of each isolate was brought to a volume of $500 \mathrm{ml}$ and 10 drops $(0.5 \mathrm{ml})$ of Tween 20 (polyoxyethylene 20 sorbitanmonolaurate, $0.02 \%$ ) were added to the suspension as surfactant. Flasks were kept at $4^{\circ} \mathrm{C}$ until the concentration was adjusted for all isolates and inoculation instigated. Equal volumes of conidial suspension from each isolate $(50 \mathrm{ml})$ were sprayed, using an atomizer pressurized by an air pump (35 kPa). After air drying the inoculated pots were placed in a polyethylene humid chamber following complete block design with five replicates (Gomez and Gomez, 1984). A saturated environment was maintained during the $30 \mathrm{~h}$ of incubation period through continues watering to kept under humid conditions $(>90 \%)$. After $30 \mathrm{~h}$ pots were removed from the humid chamber and placed in an open environment for 4 days us-

Table 1. Bipolaris sorokiniana isolates collected from different wheat growing area during 2012 and 2013 season in Bangladesh used for the pathogenic variability, aggressiveness test and origin diversity analysis

\begin{tabular}{|c|c|c|c|}
\hline Origin & $\begin{array}{l}\text { Geographic location with } \\
\text { land type }\end{array}$ & $\begin{array}{l}\text { Soil fertility } \\
\text { level }\end{array}$ & Isolate Designation \\
\hline Old Himalayan piedmont plain & Plain with high land & Low to medium & BS 61, BS-62, BS-63, BS-64 \\
\hline Active Tista flood plain & Plain with medium high land & Medium & BS-48 \\
\hline Tista meander flood plain & Plain with medium high land & Medium & BS 50, BS-51, BS -49, BS-47 \\
\hline Old Brahmaputra flood plain & Plain with medium high land & Low & BS-65, BS-67 \\
\hline High ganges river flood plain & Plain with high land & Low & $\begin{array}{l}\text { BS-1, BS-3, BS-4, BS-53, BS 8-12, BS 14-18, } \\
\text { BS 20-24, BS 28-34, BS 36-43, BS 58, 60, BS } \\
\text { 91, BS- 109, BS 118, BS 129, 130, 131, 132, } \\
\text { BS } 135-163, \text { BS } 165-169 \text { BS } 134\end{array}$ \\
\hline Lower ganges river flood plain & Plain with medium low land & Medium & $\begin{array}{l}\text { BS 68-6, BS-74, BS 70, BS 71, BS-72, BS 76, } \\
\text { BS-77, BS 78, BS 79, BS 80-89, BS } 164\end{array}$ \\
\hline Ganges tidal flood plain & Plain with medium high land & High & BS-2, BS-26, BS 35, BS-45 \\
\hline Gopalgonj-Khulna bils & Plain with medium low land & Medium & $\begin{array}{l}\text { BS 13, BS 19, BS-25, BS-27, BS-46, BS-54, } \\
\text { BS-55, BS-56, BS-57 }\end{array}$ \\
\hline Old meghna estuarine flood plain & Plain with medium low land & Medium & BS 73 \\
\hline Level barind tract & Plain with medium high land & Low & $\begin{array}{l}\text { BS 44, BS 46, BS-66, BS-90, BS 92-108, BS } \\
110-117, \text { BS 119-125, BS-127, BS-133 }\end{array}$ \\
\hline North-eastern barind tract & Plain with medium high land & Low & BS-126, BS-128 \\
\hline Madhupur tract & Plain with high land & Low & BS 5-7, BS 52, BS 59 \\
\hline
\end{tabular}


ing the same design. Leaf blotch was evaluated 5 days after inoculation by counting all lesions on the three leaves.

According to Jeger et al. (1983), seven components of disease development were recorded for each leaf of every seedling. Pathogenicity of a pathogen varies based on disease development parameters viz. infection frequency (IFnumber of lesions per square centimeter of leaf area), lesion size $\left(\mathrm{LS}-\mathrm{mm}^{2}\right)$, lesion cover (LC-percent leaf showing by lesion), necrosis (NC-percent necrotic area of the leaf), secondary spore production/leaf (SP), disease severity (DI) and percent disease index (PDI). Data on spore production per leaf were recorded after seven days of inoculation. Disease severity was measured on a standard scale of 0-5 as suggested by (Rahman et al., 2011) where, 0: refers to no visible symptoms. 1: flecks or minute lesions, 2 : small dark lesion, no distinct halo, less than 10\% area affected, 3: typical leaf with yellow halo covering $10-50 \%$ leaf area affected, 4: small but coalescing lesion covering more Than 50\% leaf area and 5: necrotic lesions and total leaf collapsed. The percent disease index (PDI) was calculated following a standard formula (McKinney, 1923).

$$
\mathrm{PDI}=\frac{\text { Sum of all disease ratings }}{\text { Total number of ratings } \times \text { Maximum grade }} \times 100
$$

Data analysis. In this study, Bipolaris sorokiniana pathogenicity and aggressiveness was measured in terms specific reaction based on seven component of disease development on susceptible cultivar. Data were subjected to univariate and multivariate analyses. Pathogenic variability among the isolates was analyzed following multivariate analysis based on components of disease development. The techniques used in multivariate analysis were: (a) Principal component analysis (PCA), (b) Principal coordinate Analysis (PCO), (c) Cluster Analysis (CLSA) and (d) Canonical variate analysis (CVA). Dendogram were constructed beteween the group by following Squared Euclidean distance method. KMEANS method was used to analyze the cluster distance. The multivariate analysis was performed by using
SPSS statistics (version 20, IBM, NY, USA). Contributions of the component to cause disease were analyzed by correlation matrices and Principal component Analysis using SPSS. Box plot were done by using STAR (statistical tools for agricultural research program, version-02, IRRI, Los Baños, Philippines) and mean data graphically computed by using MS-Excel (2010 version, Microsoft, WA, USA).

\section{Results}

Relationship among the isolates comprising the components of disease development. A total of 169 isolate of Bipolaris sorokiniana were isolated from infected wheat leaves collected from major wheat growing region (Agroecological zone and subzone) of Bangladesh during 2012 and 2013 (Table 1). From descriptive analysis in Table 2, mean values of IF, LS, LC, NC, SP, DI and PDI were 9.44/ leaf, $1.62 \mathrm{~mm}^{2}, 16.56 \%, 25.59 \%, 342.44 /$ leaf, 2.91 and $58.27 \%$, respectively. Mean value of seven components of disease development was greater than the standard error. So, significant difference among the isolates regarding the components of disease development contributes significantly to the severity of the disease.

Pathogenic pattern of Bipolaris sorokiniana. Five major clusters were identified by cluster analysis based on seven components of disease development of Bipolaris sorokiniana in wheat more or less homogeneous groups. Membership of the isolates within the cluster was correctly classified by classification statistics. $149(88.16 \%)$ isolates were distributed in cluster I, $06(3.55 \%)$ isolates in cluster II. The cluster III contains 09 (5.32\%) isolates, cluster IV contains the only $02(1.18 \%)$ isolates and lastly cluster V contains $03(1.77 \%)$ isolates (Table 3).

From KMEANS method of analysis height cluster distance was found between Cluster II and Cluster III (2096.949) and lowest cluster distance was found between Cluster III and Cluster IV (363.498) (Table 4). It revealed that pathogenic variation exist among the 169 isolates of

Table 2. Ranges and means of seven components of disease development of 169 isolates of Bipolaris sorokiniana to wheat

\begin{tabular}{cccc}
\hline Components of virulence & Minimum & Maximum & Mean \pm SE \\
\hline Infection frequency (No.) & 0.96 & 41.40 & $9.44 \pm 0.62$ \\
Lesion size (mm ${ }^{2}$ ) & 0.13 & 7.31 & $1.62 \pm 0.13$ \\
Lesion cover (\%) & 0.32 & 71.38 & $16.56 \pm 1.49$ \\
Necrosis (\%) & 0.44 & 94.27 & $25.59 \pm 2.01$ \\
Secondary Spore production (spore/leaf) & 35.56 & 2365.18 & $342.44 \pm 30.82$ \\
Disease severity index & 0.63 & 4.44 & $2.91 \pm 0.06$ \\
Percent disease index & 12.59 & 84.44 & $58.27 \pm 1.22$ \\
\hline
\end{tabular}


Table 3. Membership of 169 isolates of Bipolaris sorokiniana under different cluster based on seven components of disease development to wheat

\begin{tabular}{cccl}
$\begin{array}{c}\text { Cluster } \\
\text { number }\end{array}$ & $\begin{array}{c}\text { Number of } \\
\text { isolates }\end{array}$ & $\begin{array}{c}\text { Percentages of } \\
\text { isolates }\end{array}$ & \multicolumn{1}{c}{ Isolates } \\
\hline & & & $\begin{array}{l}\text { BS-1, BS-2, BS-3, BS-4, BS-5, BS-7, BS-8, BS-9, BS-10, BS-11, BS-12, BS-14, BS- } \\
\text { 15, BS-16, BS-17, BS-19, BS-21, BS-22, BS-23, BS-25, BS-27, BS-28, BS-32, BS- } \\
\text { I }\end{array}$ \\
& 149 & 88.16 & $\begin{array}{l}\text { 35, BS-36, BS-37, BS-39, BS-40, BS-42, BS-43, BS-44, BS-46, BS-49, BS-51 to } \\
\text { BS-142, BS-144 to BS-160 and BS-162 to BS-169 }\end{array}$ \\
II & 06 & 3.55 & BS-6, BS-18, BS-29, BS-31, BS-34, BS-134 \\
III & 09 & 5.32 & BS-13, BS-20, BS-26, BS-30, BS-38, BS-45, BS-47, BS-50, BS-143 \\
IV & 02 & 1.18 & BS-24, BS-33 \\
V & 03 & 1.77 & BS-41, BS-48, BS-161 \\
\hline
\end{tabular}

Table 4. Mean inter-cluster distance values of five clusters of 169 isolates of B. sorokiniana

\begin{tabular}{|c|c|c|c|c|c|}
\hline Cluster & I & II & III & IV & V \\
\hline I & & 437.681 & 1660.027 & 1297.112 & 648.115 \\
\hline II & & & 2096.949 & 1734.344 & 1085.573 \\
\hline III & & & & 363.498 & 1012.346 \\
\hline IV & & & & & 649.159 \\
\hline
\end{tabular}

KMEANS method of analysis.

Bipolaris sorokiniana.

Contribution of component in leaf blotch disease development. The correlation between pair of components of disease development clearly represents some aspects of relationship. All are significant at $0.05 \%$ level of Significant and positive correlation was observed between all pair of components. These positive correlations co-efficient between pair of components indicated that there has the direct relationship between the components to causes leaf blotch disease in wheat (Table 5).

From the principal components analysis extracts the eigenvalues and the eigenvectors from the correlation matrix of the components of disease development. Each principal component as associated with an eigenvalue in place of total variation that principal component accounts for. The eigenvalues sum to the number of variables analyzed. The principal components are orthogonal to (statistically independent of) each other.

The first (IF) principal component accounted for more than half (59.984\%) of the total variation. This component appeared to be general disease development traits which include the disease development process within the host because exposure to initial inoculum was much more efficient in triggering an increase in IF and an increase in genome instability in systemic tissues of locally infected plants de-

Table 5. Correlation co-efficient ${ }^{\mathrm{a}}$ among seven components of disease development of 169 isolates of Bipolaris sorokiniana

\begin{tabular}{|c|c|c|c|c|c|c|c|}
\hline Parameter $^{\mathrm{b}}$ & IF & LS & LC & $\mathrm{NC}$ & SP & DI & PDI \\
\hline \multicolumn{8}{|l|}{ IF } \\
\hline LS & 0.107 & & & & & & \\
\hline LC & 0.620 & 0.775 & & & & & \\
\hline $\mathrm{NC}$ & 0.654 & 0.756 & 0.980 & & & & \\
\hline SP & 0.142 & 0.267 & 0.228 & 0.222 & & & \\
\hline DI & 0.449 & 0.553 & 0.608 & 0.629 & 0.245 & & \\
\hline PDI & 0.428 & 0.547 & 0.592 & 0.612 & 0.237 & 0.991 & \\
\hline
\end{tabular}

${ }^{a}$ All are significant at $0.05 \%$ level of significance.

${ }^{b}$ IF- Infection frequency (No.), LS- Lesion size $\left(\mathrm{mm}^{2}\right)$, LC- Lesion cover (\%), NC- Necrosis (\%), SP- secondary.

Extraction method: pooled within groups matrices. 
Table 6. Eigenvalues and percentages of variation for seven components of disease development of wheat to169 isolates of Bipolaris sorokiniana

\begin{tabular}{cccc}
\hline $\begin{array}{c}\text { Seven components of disease } \\
\text { development }\end{array}$ & Eigenvalues & \% of total Variance & Cumulative variation \% \\
\hline I (IF) & 4.199 & 59.984 & 59.984 \\
II (LS) & 1.107 & 15.813 & 75.797 \\
III (LC) & 0.851 & 12.156 & 87.953 \\
IV (NC) & 0.754 & 10.776 & 98.729 \\
V (SP) & 0.062 & 0.890 & 99.619 \\
VI (DI) & 0.018 & 0.253 & 99.872 \\
VII (PDI) & 0.009 & 0.128 & 100.000 \\
\hline
\end{tabular}

Extraction method: principal component analysis.

IF- Infection frequency (No.), LS- Lesion size $\left(\mathrm{mm}^{2}\right)$, LC- Lesion cover (\%), NC- Necrosis (\%), SP- secondary Spore production (spore/leaf), DI- Disease severity index, PDI- Percent disease index.

pends on plant age. The second component (LS) accounted for much less of the variation (15.813\%) (Table 6). The remaining principal components all had eigenvalues of less than one which means they accounted for less variation than a single component of disease development. Infection efficiency is defined as the probability that a spore deposited on a receptive host surface produces a lesion as well as on microclimatic conditions. Lesion size accounts for a large part of the quantitative development of epidemics because lesion size prompt necrosis on the host leaf (Cowger et al., 2000). Disease severity here is a composite variable resulting from the integrated effect of infection efficiency and lesion size. It indicated that, infection frequency plays important role to cause leaf blotch disease in wheat in severe form.

Variability for aggressiveness within populations. Variation within population for quantitative traits is a basic prerequisite for adaptation. Nevertheless, apparent uniformity within a pathogen population studied on the basis of qualitative indicators does not exclude the possibility of a certain level of variability in aggressiveness. Aggressiveness is often separated into elementary quantitative traits of the pathogen life cycle. Aggressiveness is usually evaluated by directly measuring epidemic rates (Cumagun and Miedaner, 2003). In another context, authors interested in interaction between plant and pathogen genotypes at the host-plant scale measure aggressiveness through a variety of quantitative traits expressed during the host-pathogen interaction. These traits, referred to as aggressive components, are: infection efficiency, lesion size, lesion cover, necrosis, spore production rate, and percent disease index. Disease causing ability was influenced by their reproduction potential. Sporulation is expressed in spore production per unit area of diseased leaf (Clifford and Clothier, 1974).
By using STAR (IRRI) analysis it was found that mean with standard error value of secondary spore production per leaf was height in cluster number IV among the other. It revealed that, Cluster I contained the most avirulent isolates and cluster IV contain most virulent isolates (Fig. 2).

Pariaud et al. (2009) found significant intra pathotype variations for infection efficiency, lesion size and sporulation capacity among isolates of the same pathotype with differences between the least and the most aggressive isolate of up to $91 \%$. Most virulent isolates was BS-24 and BS-33 fitting in cluster- IV. Potentiality of a pathogen depends on disease-causing ability. Aggressiveness is

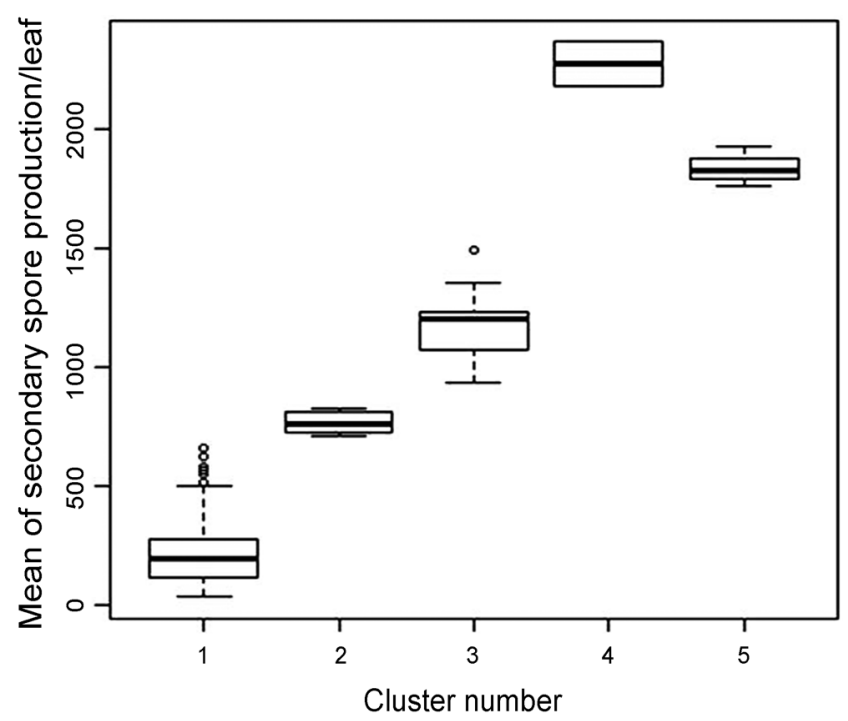

Fig. 2. Box plot of the variables: mean with standard error value of secondary spore production per leaf after seven days of inoculation in wheat. There have significant difference in mean value of secondary spore production among the five clusters. Cluster IV (4) contain height spore producing isolates and cluster I (1) contain lowest spore producing isolates of $B$. sorokiniana. 


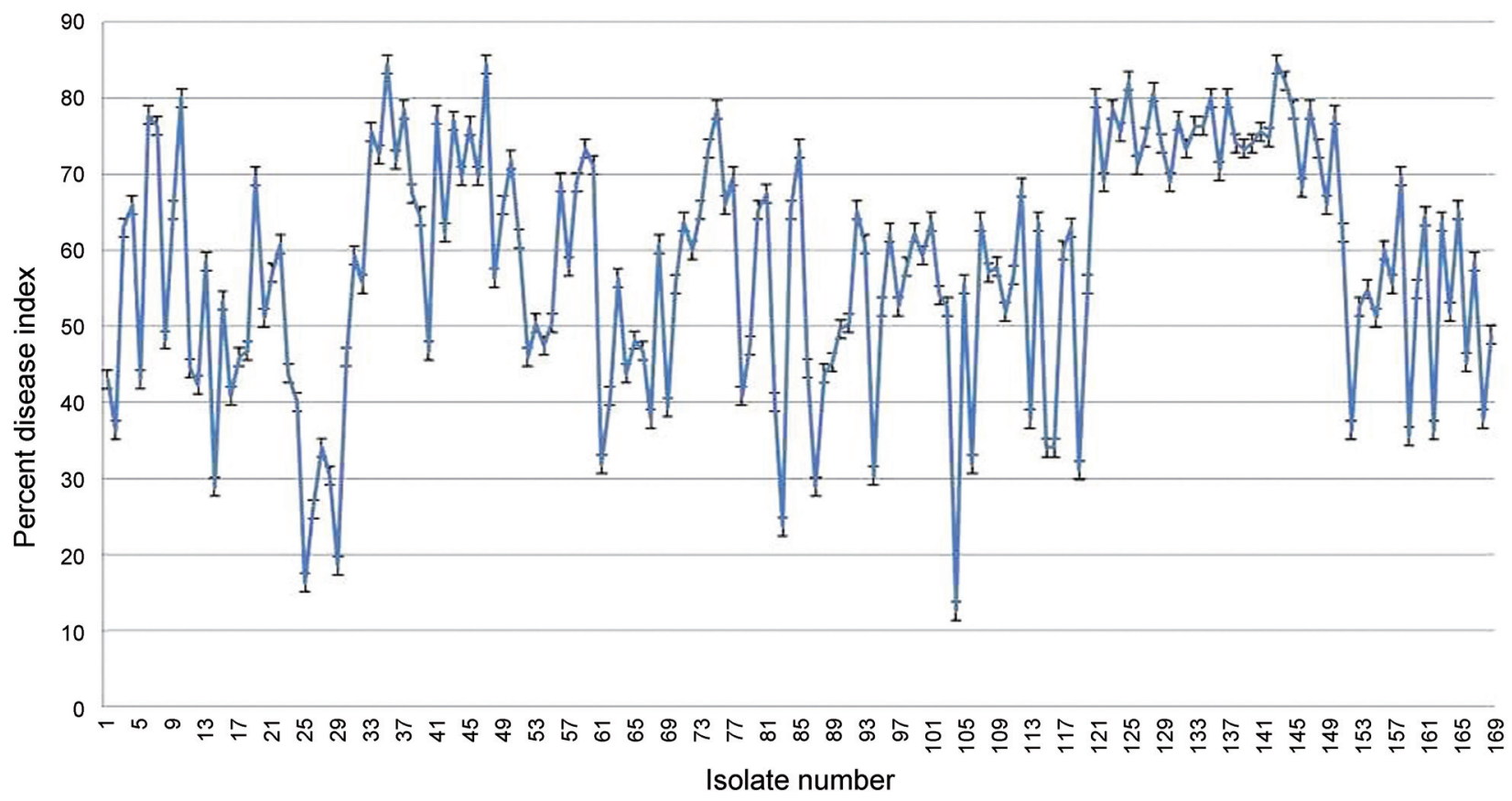

Fig. 3. Means values of percent disease index (PDI) with standard error for 169 isolates of Bipolaris sorokiniana. Here maximum PDI value was found in BS-33 isolates among the 169 isolates of Bipolaris sorokiniana. PDI is the indicator pathogenic character of a pathogen to cause disease in severe. So, BS-33 isolate of Bipolaris sorokiniana is the most aggressive isolate among the 169 isolate of Bipolaris sorokiniana.

estimated through sporulation and disease severity (Cumagun and Miedaner, 2003). BS-24 isolate produced height spore and Maximum PDI value was found in BS-33 isolate among the 169 isolate (Fig. 3, 4). From the Hierarchical cluster analysis (Fig. 5), it also proved that BS-33 and BS-24 were the most aggressive isolates among the 169 isolates. It indicates most virulent isolates belong to High Ganges River Flood Plain agro-climatic zones considered by rice-wheat cropping pattern, hot and humid weather, high land and low organic matter content in soil. It revealed that better adaptation to warmer temperatures might explain the observed changes of $B$. sorokiniana populations in the South Asia around the year 20th century.

\section{Discussion}

Pathogenic variability is consequence in disease management scheme. Pthogenicity refers to the ensemble of spe-

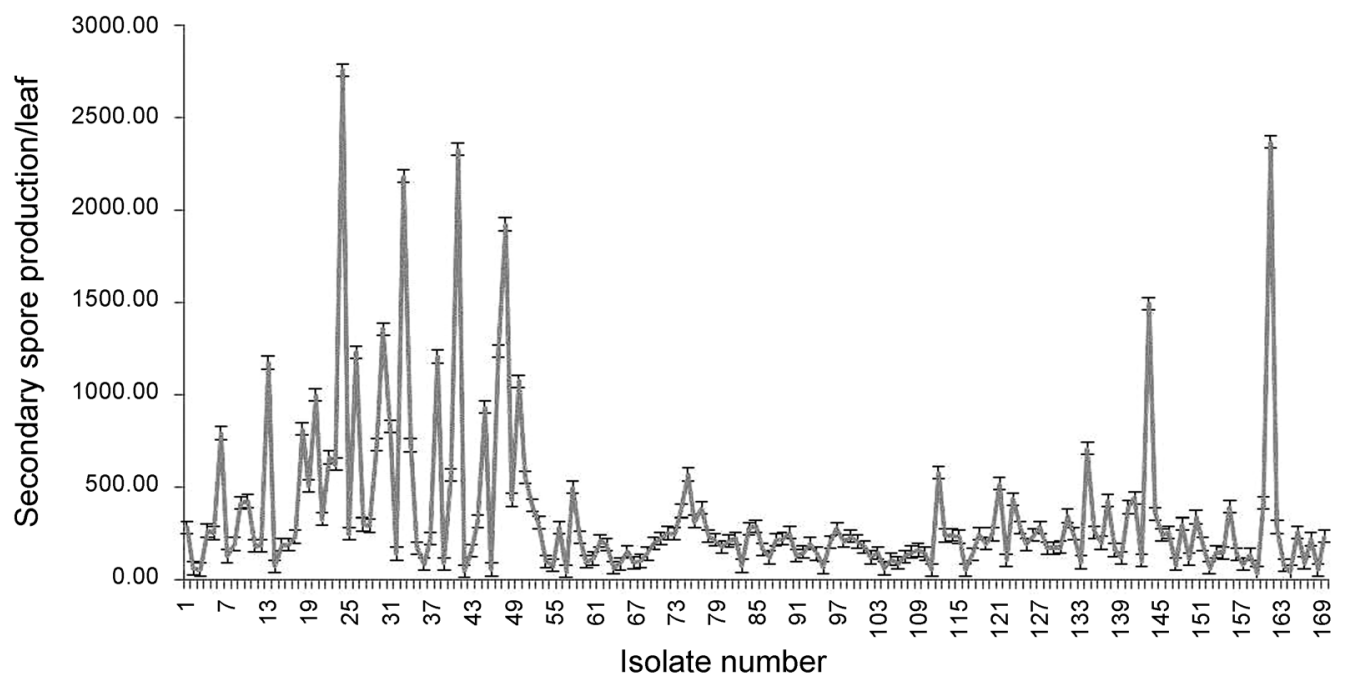

Fig. 4. Mean values of secondary spore production/leaf (SP/L) with Standard Error for 169 isolates of Bipolaris sorokiniana. Here maximum $\mathrm{SP} / \mathrm{L}$ value was found in BS24 isolates among the 169 isolates of Bipolaris sorokiniana. $\mathrm{SP} / \mathrm{L}$ is the sign of a pathogenic character to cause disease in epidemic. So, BS24 isolate of Bipolaris sorokiniana is the most virulent isolate among the 169 isolate of Bipolaris sorokiniana. 
Dendogram Using Average Linage (between group) Rescaled Distance Cluster Combine
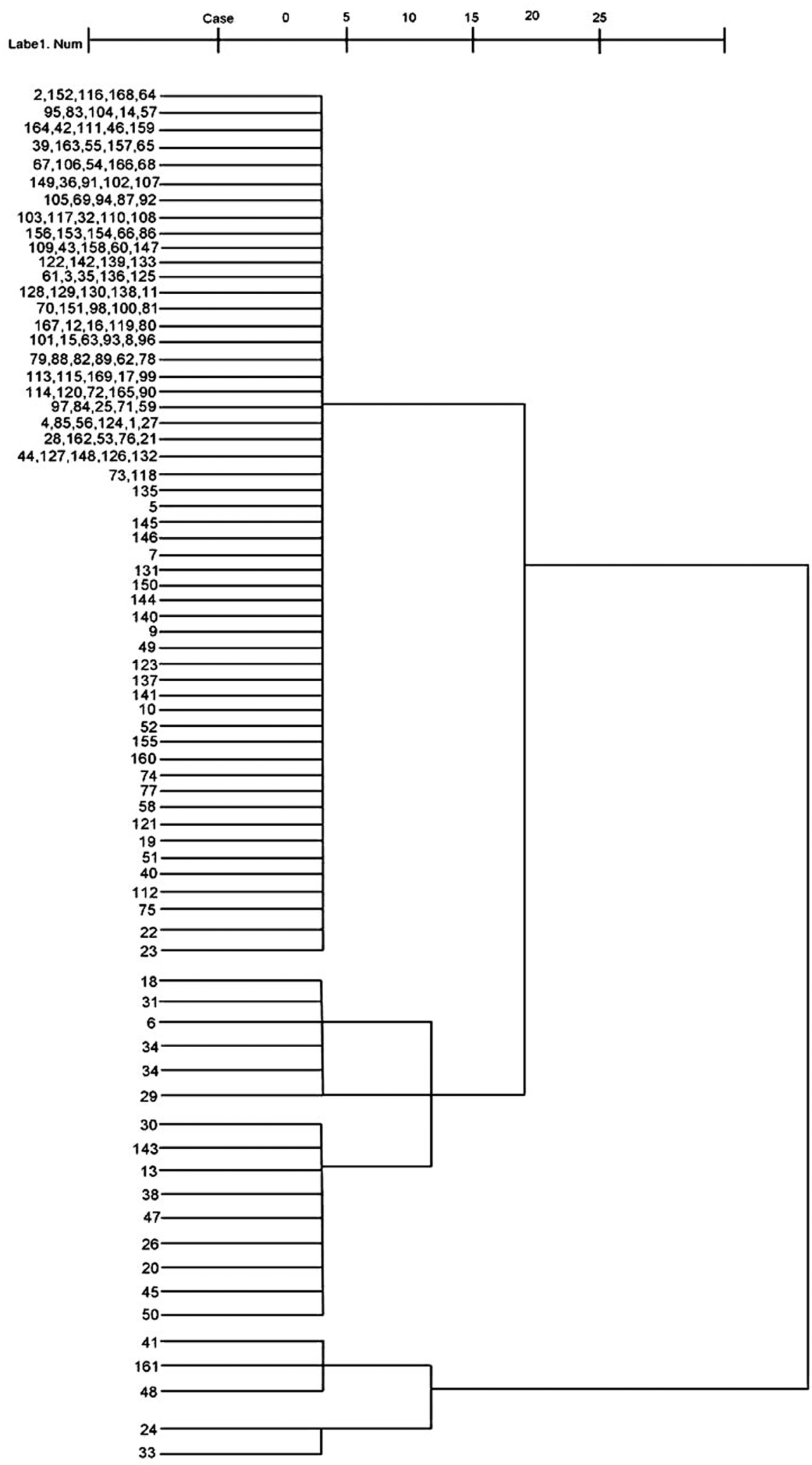

Fig. 5. Dendogram showing Hierarchical cluster groups (less virulent to more virulent) isolates of $B$. sorokiniana bases on seven component of disease development in wheat. Here less virulent isolates are BS-2, BS-152, BS-116, BS-64 and BS-168 and most virulent isolates are BS-33 and BS-24. 
cific and nonspecific disease-causing abilities (Van der Plank, 1968). By contrast, in this study, the term "virulence" was referring to the collaborative of specific disease causing abilities based on components of disease development. Studies conducted to characterize in pathogenic variability of $B$. sorokiniana isolates from distinct geographical areas showed that significant differences exist in host response. Similar result achieved by Maraite et al. (1998). Milus et al. (2006) found that two isolates belonging to the same pathotype have significant differences in aggressiveness (lesion expansion rate, sporulation and infection efficiency). The pathogenic variability and aggressiveness of this pathogen seems to increase over time (Jaiswal et al., 2007). Similar observations in Asad et al., 2007 the stability of resistant genetic strains remained essential considering that $B$. sorokiniana the principal pathogen forms a continuum of strains differing in aggressiveness. The clustering was independent of the eco-geographical origin of the isolates but reflected the virulence spectra of the isolates. That is, all highly virulent isolates diverged significantly from the avirulent ones. In this study, five cluster groups were found based on seven components of disease development in wheat and generate virulence difference in different agroclimate. Whereas, clustering were independent of the eco-geographical origin of the isolates but reflected the virulence spectra of the isolates. That is, all highly virulent isolates diverged significantly from the avirulent ones. Chand et al. (2003) outcome also publicized that the isolates of $B$. sorokiniana could be grouped five categories based on their morphological and pathological traits. Tinline (1961) proposed that mutation, heterokaryose and hybridization would increase the possibility of pathogenic variability among the isolates. Aggarwal et al. (2010) confirmed differences in disease causing ability of different strains on a set of wheat genotypes.

Positive correlation between the seven components of disease development was found. The more general question as to the independence of components could be answered simply by inspection of Table 5 and 6 , by the comparison of correlation coefficients. Factor analysis indicated that pathogen-induced infection frequencies related possibly to spore production per unit area were major components of disease development to Bipolaris sorokiniana. According to Jeger et al. (1983) report, sporulation and infection efficiency explore their input to develop leaf blotch disease.

Present study discovered that cluster IV (BS 24 and BS 33 ) includes the most virulent isolates and cluster I includes the least virulent isolates. Most virulent isolates BS 24 and BS 33 among the 169 isolates belong in High ganges river flood plain due to the rice-wheat cropping pattern and appropriate combination of inoculum, high and humid weather and growth stage of wheat. It appears that there have differences in pathogenic isolates and geographic origins. These findings agreed to Duveiller et al. (1998b) and Chaurasia et al (2000). It also seems that separating pathogenic characters help in finding a correlation between isolate variability and agroclimatic origin. Different studies to characterize $B$. sorokiniana isolates from distinct agroclimatic areas showed that significant differences exist in host response (Mahto et al., 2012) and genetic composition. Although the isolates from five different groups were distinct in their virulence, positive relationship was found between these traits and the agroclimaic origin of the isolates. Variation was found among the isolates from traditional and non traditional wheat growing areas. Mundt et al. (2002) investigated the potential association of aggressiveness variation among isolates and phylogenetic classification. He suggested that mutations leading to increased aggressiveness had rapidly accumulated within the phylogenetic lineages. Most studies linking aggressiveness components to the environment have aimed to understand quantitative epidemic development in a range of environmental situations, only considering the species level. In some cases, however, it has been demonstrated that the relative fitness of different genotypes within the same pathogen species can vary according to environmental effects (Milus et al., 2006) and a few studies have attempted to link pathogen population structures and agroclimate. These differences may have contributed to the recently expanded increase global warming or environmental alteration. These studies suggest that effect of agroclimatic condition on pathogen aggressiveness may affect parasite performance through genotype-by-environment interactions (Price et al., 2004; Laine, 2008) with a fitness estimate based on latent period and spore production.

Mahto et al. (2012) suggested that the pathogenic variability in B. sorokiniana could be attributed to the multinucleate condition of mycelium and conidia, with subsequent heterokaryosis. These studies illustrate that the high pathogenic variability of $B$. sorokiniana creates difficulty in identifying and determining the appropriate measures for disease management strategies (Zhong and Steffenson, 2001). It also inferred that a large amount of virulence/ aggressiveness diversity exists in Bipolaris sorokiniana and differences in aggressiveness in terms of agroclimatic origins. These agroclimatic conditions should be used in screening of lines in breeding programmes and this strength applicable in epidemiological studies. 


\section{Acknowledgments}

The authors are thankful to the ministry of education, Bangladesh for financial support to conduct this study.

\section{References}

Adhikary, S. K., Quddus, K. G., Samia, T. and Sultana, S. 2015. Effect of fungicides against Bipolaris Sorokiniana isolates collected from different wheat growing regions of bangladesh. Mycopath 13:81-88.

Adhikary, S. K. and Mian, I. H. 2005. Variation in virulence of isolates of Bipolaris sorokiniana (Sacc. In Sorok.) shoemaker on wheat in Bangladesh. J. Asiat. Soc. Bangladesh, Sci. 31:39-46.

Alam, B. K., Banu, S. P. and Shaheed, M. A. 1998. Occurrence and significance of spot blotch in Bangladesh. In: Proceedings of the international workshop on Helminthosporium diseases of wheat: spot blotch and tan spot (February 9-14), eds. by E. Duveiller, H. J. Dubin, J. Reeves and A. Mcnab, pp. 63-66. CIMMYT, El Batán, Mexico.

Aggarwal, R., Singh, V. B., Shukla, R., Gurjar, M. S., Gupta, S. and Sharma, T. R. 2010. URP-based DNA fingerprinting of Bipolaris sorokiniana isolates causing spot blotch of wheat. $J$. Phytopathol. 158:210-216.

Asad, S., Iftikhar, S., Munir, A., Ahmad, I. and Ayub, N. 2007. Pathogenic diversity in Bipolaris Sorokiniana isolates collected from different wheat growing areas of the punjab and NWFP of Pakistan. Pak. J. Bot. 39:2225-2231.

Basheer-Salimia, R. and Atawnah, S. 2014. Morphological features, yield components and genetic relatedness of some wheat genotypes grown in Palestine. World Journal of Agricultural Research 2:12-21.

BBS. 2016. Statistical year book. Bangladesh bureau of statistics. Ministry of Planning, Government of the People's Republic of Bangladesh.

Chand, R., Pandey, S. P., Singh, H. V., Kumar, S. and Joshi, A. K. 2003. Variability and its probable cause in natural populations of spot blotch pathogen Bipolaris Sorokiniana of wheat ( $T$. Aestivum L.) in India. J. Plant Dis. Protect. 110:27-35.

Chaurasia, S., Chand, R. and Joshi, A. K. 2000. Relative dominance of Alternaria triticina Pras. et Prab. and Bipolaris sorokiniana (Sacc.) Shoemaker in different growth stages of wheat (T. aestivum L.). J. Plant Dis. Protect. 107:176-181.

Clifford, B. C. and Clothier, R. B. 1974. Physiologic specialization of Puccinia hordei on barley hosts with non-hypersensitive resistance. Trans. Br. Mycol. Soc. 63:421-430.

Cowger, C., Hoffer, M. E. and Mundt, C. C. 2000. Specific adaptation by Mycosphaerella graminicola to a resistant wheat cultivar. Plant Pathol. 49:445-451.

Cumagun, C. J. R. and Miedaner, T. 2003. Aggressiveness of 42 isolates of Gibberella zeae (Fusarium graminearum) in wheat under field and greenhouse conditions. J. Plant Dis. Protect. 110:554-559.
Duveiller, E., Dubin, H. J., Reeves, J. and McNab, A. 1998a. Proc. int. workshop Helminthosporium diseases of wheat: spot blotch and tan spot (9-14 Feb. 1997). CYMMYT, El Batan, Mexico.

Duveiller, E., García, I., Toledo, J., Franco, J., Crossa, J. and Lopez, F. 1998b. Evaluation of resistance to spot blotch of wheat in Mexico: improvement of disease assessment in the field and under controlled conditions. In: Proc. int. workshop Helminthosporium diseases of wheat: spot blotch and tan spot (9-14 Feb. 1997), eds. by E. Duveiller, H. J. Dubin, J. Reeves and A. McNab, pp. 171-181. CYMMYT, El Batán, Mexico.

Gomez, K. and Gomez, A. 1984. Statistical procedures for agricultural research. 2nd ed. John Wiley \& Sons, NY, USA.

Jaiswal, S. K., Sweta, Prasad, L. C., Sharma, S., Kumar, S., Prasad, R., Pandey, S. P., Chand, R. and Joshi, A. K. 2007. Identification of molecular marker and aggressiveness for different groups of Bipolaris Sorokiniana isolates causing spot blotch disease in wheat (Triticum Aestivum L.). Curr. Microbiol. 55:135-141.

Jeger, M. J., Gareth Jones, D. and Griffiths, E. 1983. Components of partial resistance of wheat seedlings to Septoria nodorum. Euphytica 32:575-584.

Joshi, A. K., Ortiz-Ferrara, G., Crossa, J., Singh, G., Alvarado, G., Bhatta, M. R., Duveiller, E., Sharma, R. C., Pandit, D. B., Siddique, A. B., Das, S. Y., Sharma, R. N. and Chand, R. 2007. Associations of environments in South Asia based on leaf blotch disease of wheat caused by Cochliobolus sativus. Crop Sci. 47:1071-1081.

Joshi, A. K., Kumar, S., Chand, R. and Ortiz-Ferrara, G. 2004. Inheritance of resistance to spot blotch caused by Bipolaris sorokiniana in spring wheat. Plant Breeding 123:213-219.

Joshi, A. K. and Chand, R. 2002. Variation and inheritance of leaf angle, and its association with spot blotch (Bipolaris sorokiniana) severity in wheat (Triticum aestivum). Euphytica 124:283-291.

Kumar, S., Kumari, J., Bansal, R., Kuri, B. R., Singh, A. K., Wankhede, D. P., Akhtar, J. and Khan, Z. 2015. Slow rustingan effective way to achieve durable resistance against leaf rust in wheat. eWIS 120:26-34.

Laine, A. L. 2008. Temperature-mediated patterns of local adaptation in a natural plant-pathogen meta population. Ecol. Lett. 11:327-337.

Lancashire, P. D. and Jones, D. G. 1985. Components of partial resistance to Septoria nodorum in winter wheat. Ann. Appl. Biol. 106:541-553.

Mahto, B. N., Gurung, S., Nepal, A. and Adhikari, T. B. 2012. Morphological, pathological and genetic variations among isolates of Cochliobolus sativus from Nepal. Eur. J. Plant Pathol. 133:405-417.

Maraite, H., Di Zinno, T., Longreé, H., Daumerie, V. and Duveiller, E. 1998. Fungi associated with foliar blight of wheat in warmer areas. In: Proceedings of the international workshop on helminthosporium diseases of wheat: spot blotch and tan spot (February 9-14, 1997), eds. by E. Duveiller, H. J. 
Dubin, J. Reeves and A. Mcnab, pp. 293-300. CIMMYT, El Batán, Mexico.

Mckinney, H. H. 1923. influence of soil temperature and moisture on infection of wheat seedlings by Helminthos poriumsativum. J. Agric. Res. 26:195-217.

Milus, E. A., Seyran, E. and McNew, R. 2006. Aggressiveness of Puccinia Striiformis f.sp. tritici isolates in the South-Central United States. Plant Dis. 90:847-852.

Mundt, C. C., Nieva, L. P. and Vera Cruz, C. M. 2002. Variation for aggressiveness within and between lineages of Xanthomonas oryzae pv. oryzae. Plant Pathol. 51:163-168.

Pariaud, B., Ravigné, V., Halkett, F., Goyeau, H., Carlier, J. and Lannou, C. 2009. Aggressiveness and its role in the adaptation of plant pathogens. Plant Pathol. 58:409-424.

Price, J. S., Bever, J. D. and Clay, K. 2004. Genotype, environment, and genotype by environment interactions determine quantitative resistance to leaf rust (Coleosporium asterum) in Euthamia graminifolia (Asteraceae). New Phytol. 162:729743.

Rahman, M. M., Alam, A. K. M. M., Naher, N., Sharifuzzaman, S. M. and Uddin, M. A. N. 2011. Reaction of barley genotypes to Bipolaris sorokiniana. Bangladesh Journal of Agricultural
Research 36:123-128.

Robert, V., Stegehuis, G. and Stalpers, J. 2005. The MycoBank engine and related databases. URL http://www.mycobank. org/.

Rosegrant, M. W., Agcaoili-Sombilla, M. C. and Perez, N. D. 1995. Global food projections to 2020: implications for investment. Food, agriculture, and the environment discussion paper 5. International Food Policy Research Institute, Diane Publishing, USA.

Singh, D. P., Singh, S. K. and Singh, I. 2016. Assessment and impact of spot blotch resistance on grain discoloration in wheat. Indian Phytopath. 69:363-367.

Tinline, R. D. 1961. Cochliobolus sativus: IV drug resistant, color and nutritionally exacting mutants. Can. J. Bot. 39:16951704.

Van der Plank, J. E. 1963. Plant diseases: epidemics and control. Academic Press.

Van der Plank, J. E. 1968. Disease resistance in plants. Academic. 2nd ed. Academic, Orlando, FL, USA.

Zhong, S. and Steffenson, B. J. 2001. Virulence and molecular diversity in Cochliobolus sativus. Phytopathology 91:469-476. 